УДК $582.24(477)$

Viunnyk V.O.: orcid.org/0000-0002-2450-0435

Leontyev D.V.: https://orcid.org/0000-0002-4122-1091, Scopus ID 54079866200

\title{
БІОРІЗНОМАНІТТЯ ТА ЕКОЛОГІЯ МІКСОМІЦЕТІВ БОТАНІЧНОГО ЗАКАЗНИКА МІСЦЕВОГО ЗНАЧЕННЯ «ШАРІВСЬКИЙ» (ХАРКІВСЬКА ОБЛ., УКРАЇНА)
}

\author{
(C) В’юнник В.О., Леонтьєв Д.В. \\ Харківський національний педагогічний університет імені Г.С. Сковороди \\ vjnnuk@gmail.com \\ https://doi.org/10.34142/2708-5848.2020.22.2.02
}

\begin{abstract}
Дослідження біоти міксоміцетів ботанічного заказника місцевого значення «Шарівський», проведене у період 26 серпня - 15 листопада 2020 р. дозволило виявити 35 видів, що відносяться до 18 родів, 8 родин, 7 порядків та 2 підкласів класу Мухотусеtes. Індекс різноманіття Маргалєфа для дослідженої біоти склав 18.6 (використовували десятковий логарифм), а індекс Менхініка - 4.1, що свідчить про відносно високий рівень різноманіття. Індекс Шеннона склав 1.4, індекс Сімпсона - 0.04, а індекс Пілоу - 0.3, що вказує на високий рівень вирівненості видового спектру досліджуваної біоти. Розподіл виявлених видів за підкласами є майже однаковим, по 18 і 17 видів у двох підкласах, Lucisporomycetidae та Columellomycetidae відповідно. Найбільша кількість видів відноситься до порядків Stemonitidales та Physarales (по 8 видів), Trichiales (7). Серед родин провідне становище займає Physaraceae (8), Trichiaceae (7) та Amaurochaetaceae (6). Серед родів Cribraria Pers. (5), Arcyria F.H. Wigg., Trichia Haller та Physarum Pers. по 3 види. Більшість видів відносяться до ксилофільної екологічної групи (31; 88.6\%), 3 види $(8.6 \%)$ до кортикофільної і лише 1 вид (2.9\%) до бріофільної, а Arcyria pomiformis продемонструвала змішану екологічну стратегію. Ці дані дають змогу охарактеризувати біоту міксоміцетів заказника як ксилофільну, що є звичайним для лісостепу. Серед субстратоутворюючих видів рослин, найбільше видів міксоміцетів було виявлено на Pinus sylvestris (24), всі інші субстратоутворюючі види значно поступаються за цим показником Quercus robur (7), Populus tremula та Fraximus excelsior по 4 види. Досліджувана територія раніше не була об'єктом дослідження біоти міксоміцетів, тому всі виявленні види є новими для неї. Один з виявлених видів, Cribraria persoonii Nann.-Bremek вперше наводиться для лісостепової зони України та українського Лівобережжя, знайдена на мертвій деревині P. sylvestris.
\end{abstract}

Ключові слова: екологічні групи, метод вологої камери, таксономічна структура, Харківський лicocmen.

Ботанічний заказник місцевого значення «Шарівський» (далі ЗШ), створений у 1984 р., розташований в околицях с. Шарівка, на правому березі р. Мерчик, лівої притоки р. Мерла. Площа заказника складає 46 га. Адміністративно територія заказника належить до Богодухівського району Харківської обл. [10].

Згідно 3 ботаніко-геоботанічним районуванням України, територія ЗШ належить до Середньоросійської лісостепової підпровінції Східноєвропейської провінції Європейсько-Сибірської лсостепової області [3]. Відповідно до прийнятого в вітчизняній мікології районуванням, територія заказника знаходиться у межах Харківського Лісостепу [2].
Вся територія ЗШ вкрита лісом. Кленово-липово-дубовий ліс, розташований у північно-східній частині заказника, характеризується домінуванням в першому ярусі Quercus robur L. 3 домішками Acer platanoides L. та Tilia cordata Mill.; трапляється також Fraximus excelsior L. У другому ярусі лісу переважають A. platanoides та Ulmus grabra Huds., рідко - Betula pendula Roth., Malus sylvestris L., Pyrus commulis L., Populus tremula L., Salix spp.; трапляються домішки Robinia pseudoacacia L., Acer negundo та Acer pseudoplatanus L. Підлісок сформований головним чином Corylus avellana L., Euonymus europaeus L., E. verrucosus Scop. та Sambucus nigra L.

Бір, розташований на піщаній терасі p. Мерчик, відрізняється домінуванням 
Pinus sylvestris L. Другий ярус у цьому угрупованні не виражений, а у третьому переважають $B$. pendula, $Q$. robur, A. platanoides, $P$. commulis та $T$. cordata. Підлісок складають Prunus spinosa L. Rosa canina L., Chamaecytisus ruthenicus Fisch. ex Woloszcz, E. europaeus ta E. verrucosus.

\section{МАТЕРІАЛИ І МЕТОДИ}

Матеріал дослідження було зібрано у період з 26 серпня по 15 листопада 2020 р. Відбір зразків проводився за загальноприйнятою методикою, 3 використанням польових зборів та методу вологої камери [9].

Маршрути польових зборів будувались таким чином, щоб охопити якомога більшу частину території ЗШ (Рис. 1). Під час екскурсій оглядались стовбури живих дерев, сухостій, відмерла дерева, пні, опад та підстилка. В разі виявлення зрілих
Сосново-дубовий субір знаходиться в центральній частині ЗШ, в зоні переходу від бору до кленово-липово-дубового лісу. Це угруповання характеризується переважанням у першому ярусі $P$. sylvestris та $Q$. robur та змішаним складом підліску.

плодових тіл міксоміцетів, їх відокремлювали від субстрату та переносили в картонні коробки 5.0×3.5 cм, фіксуючи клеєм. Для запобігання пошкодження колекції комахами [1] проводилось проморожування зразків в морозильній камері при $-5^{\circ} \mathrm{C}$.

Географічні координати місцезнаходжень визначали за допомогою додатку GPS Status для Android. Усього було зареєстровано 75 місцезнаходжень (Рис. $1)$.

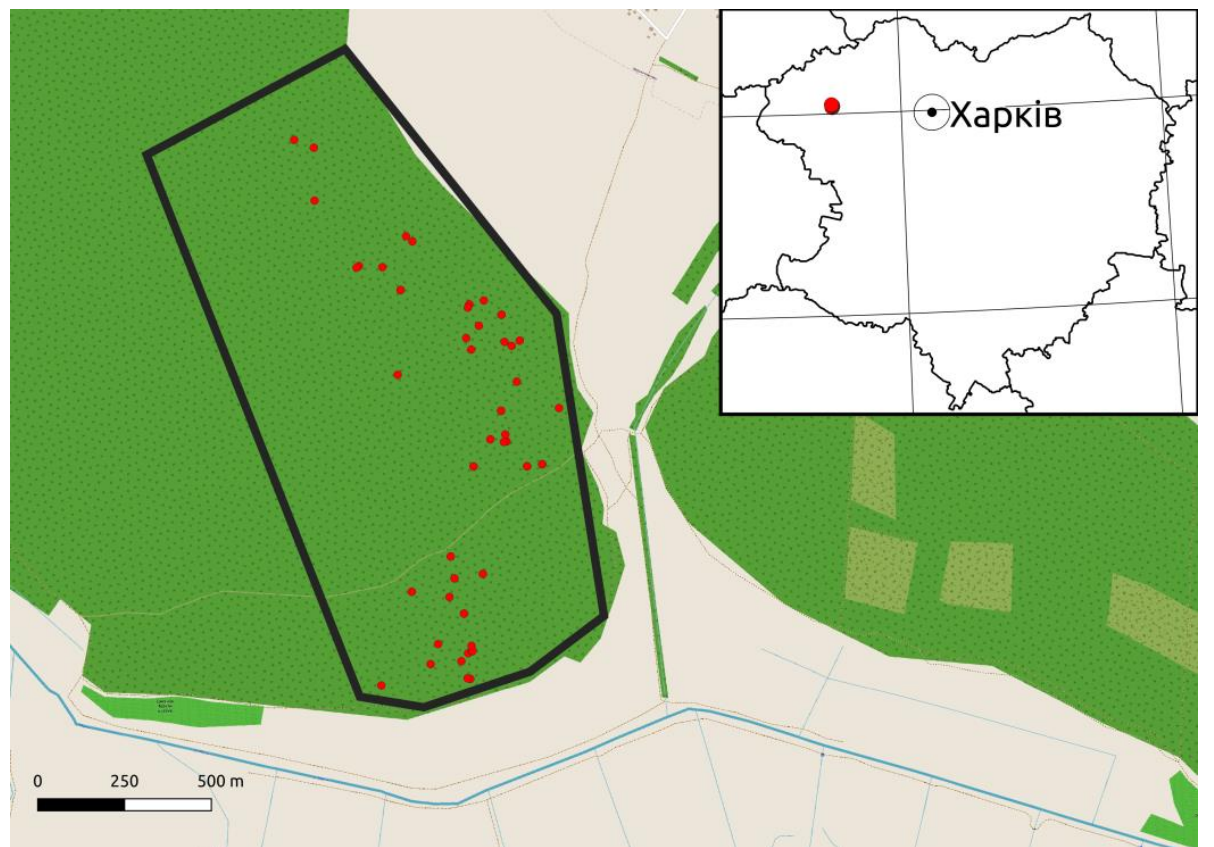

Puc. 1. Карта досліджуваної території. Точки відповідають координатам зібраних зразків, контур - межам заказника «Шарівський». На врізці показане розташування заказника на території Харківської обл.

Для виявлення міксоміцетів методом вологої камери [5, 9] збирали кору живих дерев діаметром 20-40 см, на висоті 1.5 м. Субстрат викладали в чашки Петрі на фільтрувальний папір, який одразу після цього зволожували. Чашки тримали при кімнатній температурі під розсіяним природнім освітленням. Огляд камер здійснювали протягом двох місяців до повного висихання субстрату, 3 інтервалом в 3 дні протягом перших двох тижнів експерименту, далі - кожні 7 днів. 
В разі виявлення зрілих плодових тіл міксоміцетів їх переносили до картонних коробок.

Ідентифікацію видів здійснювали 3 використанням визначника М. Пуляна зі співавт. [8]. Матеріал дослідження зберігається у мікологічній секції Наукового

\section{РЕЗУЛЬТАТИ}

У результаті проведеного дослідження на території ЗШ було виявлено 35 видів, що за систематикою Леонтьєва зі співавт. [7] гербарію Харківського національного педагогічного університету ім. Г.С. Сковороди (CWP). Мікрфотографування та вимірювання мікроскопічних структур здійснювали за допомогою цифрової камери Segeta Digital Cam 18MP (Китай) та додатку ToupView для Windows.

належать до 18 родів, 8 родин, 7 порядків та 2 підкласів класу Myхоmycetes (Табл. $1)$.

Таблиия 1

Систематичний список міксоміцетів заказника місцевого значення «Шарівський»

\begin{tabular}{|c|c|c|}
\hline $\begin{array}{l}\text { № } \\
\text { 3/II }\end{array}$ & Види & Субстрат \\
\hline \multicolumn{3}{|c|}{ КЛАС МYХOMYCETES G. Winter } \\
\hline \multicolumn{3}{|c|}{$\begin{array}{l}\text { ПІДКЛАС LUCISPOROMYCETIDAE } \\
\text { Leontyev, Schnittler, S.L. Stephenson, Novozhilov \& Shchepin }\end{array}$} \\
\hline \multicolumn{3}{|c|}{ CRIBRARIALES T. Macbr. } \\
\hline \multicolumn{3}{|c|}{ Cribrariaceae Corda } \\
\hline 1. & Cribraria argillacea (Pers.) Pers. & wPS \\
\hline 2. & $\begin{array}{l}\text { C. cancellata (Batsch) Nann.-Bremek. } \\
\text { var. cancellata }\end{array}$ & wPS \\
\hline 3. & C. intricata Schrad. & wPS \\
\hline 4. & C. persoonii Nann.-Bremek. & wPS \\
\hline 5. & C. vulgaris Schrad. & wPS \\
\hline \multicolumn{3}{|c|}{ RETICULARIALES Leontyev, Schnittler, S.L. Stephenson, Novozhilov \& Shchepin } \\
\hline \multicolumn{3}{|c|}{ Reticulariaceae Chevall. } \\
\hline 6. & Lycogala epidendrum (L.) Fr. sensu lato & wPS wFE wPT wQR wTC \\
\hline 7. & L. exiguum Morgan. & wPS \\
\hline 8. & Reticularia lycoperdon Bull. & wPS wFE \\
\hline 9. & Tubifera applanata Leontyev \& Fefelov & wPS \\
\hline \multicolumn{3}{|c|}{ LICEALES E. Jahn } \\
\hline \multicolumn{3}{|c|}{ Liceaceae Chevall. } \\
\hline 10. & Licea operculata (Wingate) G.W. Martin & $\mathrm{b}^{*} \mathrm{QR}$ \\
\hline 11. & L. variabilis Schrad. & wPS \\
\hline \multicolumn{3}{|c|}{ TRICHIALES T. Macbr. } \\
\hline \multicolumn{3}{|c|}{ Trichiaceae Chevall. } \\
\hline 12. & Arcyria incarnata (Pers. ex J.F. Gmel.) Pers. & wPS \\
\hline 13. & A. obvelata (Oeder) Onsberg & wPS \\
\hline 14. & A. pomiformis (Leers) Rostaf. & wPS, b*QR, b*TC \\
\hline 15. & $\begin{array}{l}\text { Metatrichia vesparia (Batsch) Nann.-Bremek. ex } \\
\text { G.W. Martin \& Alexop. }\end{array}$ & wPT wQR \\
\hline 16. & Trihia decipiens (Pers.) T. Macbr. var. decipiens & wPT \\
\hline 17. & T. scabra Rostaf. & wQR \\
\hline 18. & T. varia (Pers. ex J.F. Gmel.) Pers. & wTC \\
\hline
\end{tabular}




\begin{tabular}{|c|c|c|}
\hline \multicolumn{3}{|c|}{$\begin{array}{l}\text { ПІДКЛАС СОLUMELLOMYСЕTIDAE Leontyev, Schnittler, S.L. Stephenson, } \\
\text { Novozhilov \& Shchepin }\end{array}$} \\
\hline \multicolumn{3}{|c|}{ ECHINOSTELIALES G.W. Martin } \\
\hline \multicolumn{3}{|c|}{ Echinosteliaceae Rostaf. ex Cooke } \\
\hline 19. & Echinostelium minutum de Bar & $\mathrm{b}^{*} \mathrm{QR}$ \\
\hline \multicolumn{3}{|c|}{ STEMONITIDALES T. Macbr. } \\
\hline \multicolumn{3}{|c|}{ Stemonitidaceae Fr. } \\
\hline 20. & Stemonitis axifera (Bull.) T.Macbr. & wPS \\
\hline 21. & S. fusca Roth. & wPS \\
\hline \multicolumn{3}{|c|}{ Amaurochaetaceae Rostaf. ex Cooke } \\
\hline 22. & Comatricha pulchella (C. Bab.) Rostaf. & wPS \\
\hline 23. & C. nigra (Pers.) J. Schröt. & wPS \\
\hline 24. & Enerthenema papillatum (Pers.) Rostaf. & wPS \\
\hline 25. & Paradiacheopsis fimbriata (G. Lister \& Cran) Hertel & wPS \\
\hline 26. & P. solitaria (Nann.-Bremek.) Nann.-Bremek. & wPS \\
\hline 27. & $\begin{array}{l}\text { Stemonitopsis amoena (Nann.-Bremek.) Nann.- } \\
\text { Bremek. }\end{array}$ & wPS \\
\hline \multicolumn{3}{|c|}{ PHYSARALES T. Macbr. } \\
\hline \multicolumn{3}{|c|}{ Physaraceae Chevall. } \\
\hline 28. & Badhamia capsulifera (Bull.) Berk. & WAN \\
\hline 29. & B. melanospora Speg. & wFE \\
\hline 30. & $\begin{array}{l}\text { Craterium leucocephalum (Pers. ex J.F.Gmel.) } \\
\text { Ditmar. }\end{array}$ & wQR \\
\hline 31. & $\begin{array}{l}\text { Fuligo leviderma H.Neubert, Nowotny \& } \\
\text { K.Baumann. }\end{array}$ & wPT \\
\hline 32. & $\begin{array}{l}\text { F. septica (L.) F.H.Wigg. var. flava (Pers.) Y. } \\
\text { Yamam. }\end{array}$ & wPS \\
\hline 33. & Physarum album (Bull.) Chevall. & wPS \\
\hline 34. & Ph. diderma Rostaf. & wFE, m \\
\hline 35. & Ph. viride (Bull.) Pers. & wPS \\
\hline
\end{tabular}

Пр и м і тк и :

Типи субстратів: b* - кора живого дерева, w - мертва деревина, $\mathrm{m}$ - живі мохоподібні. Субстратоутворюючі рослини: $\mathrm{AN}-A$. negundo, $\mathrm{FE}-$ F. excelsior, $\mathrm{PS}-P$. sylvestris, $\mathrm{PT}-P$. tremula, QR Q. robur, TC - T. cordata,

Індекс різноманіття Маргалєфа для дослідженої біоти склав 18.6 (використовували десятковий логарифм), а індекс Менхініка - 4.1, що свідчить про відносно високий рівень різноманіття. Індекс Шеннона склав 1.4, індекс Сімпсона - 0.04, а індекс Пілоу - 0.3, що вказує на високий рівень вирівненості видового спектру досліджуваної біоти [4].

Усі виявлені види $є$ новими для території заказника. Один 3 видів, Cribraria persoonii, вперше наводиться для лісостепової зони України та українського Лівобережжя. Нижче подано опис знахідки.
Cribraria persoonii Nann.-Bremek., Proc. Kon. Ned. Akad. Wetensch., C. 74(4):353 (1971) (Рuc. 1). Спорокарпи у невеликих групах, 1.3-1.8 мм завв. Ніжка в 1-3 рази перевищує діам. споротеки, темно-коричневого кольору, поздовжньоскладчаста, викривлена по довжині, прямостояча, нагорі дещо нахилена. Споротека 0.4-0.7 мм діам. Чашечка темно-коричнева, іiі край зубчастий, потовщений, заповнений диктидиновими гранулами. Передіальна сіточка утворена видовженими, зірчастими вузликами, що мають по кілька вільних кінців. Диктидинові гранули близько $1.5 \mu \mathrm{m}$ діам. 
Спори в масі жовтовато-охяні, в Німеччина, Греція, Данія, Іспанія, Литва, наскрізному світлі незабарвлені, 3 Ліхтенштейн, Нідерланди, Норвегія, Поржовтими маслянистими включеннями, тугалія, Словаччина, Словенія, Фінляндія, округлі, $7 \mu \mathrm{m}$ діам.

Знахідки в ЗШ: на мертвій деревині P. sylvestris, $50.03748^{\circ}$ пн. ш., $35.47586^{\circ} \mathrm{cx}$. Франція, Швейцарія, Швеція, Естонія; Азія: Індія, Японія; Пн. Америка: Канада, д.

Загальне поширення: Європа: Австрія, Бельгія, Великобританія,
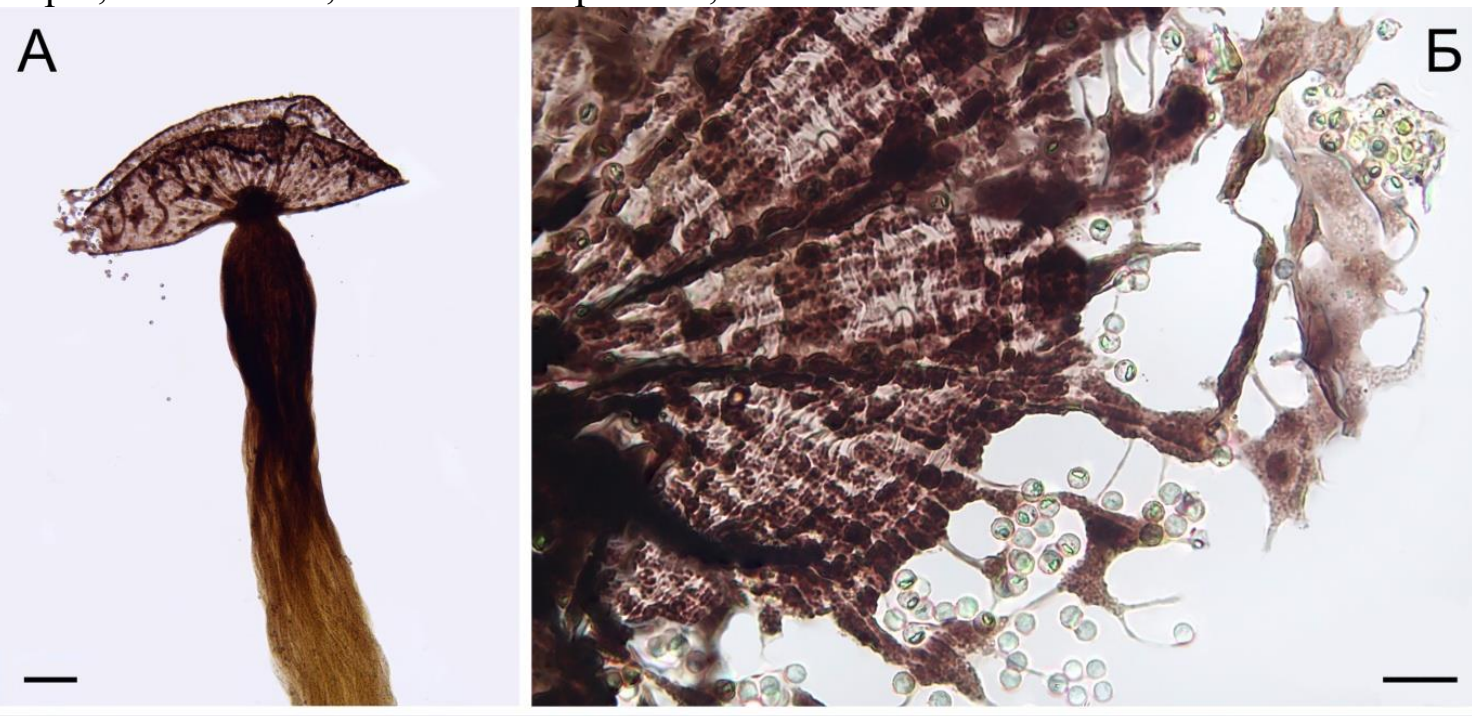

B

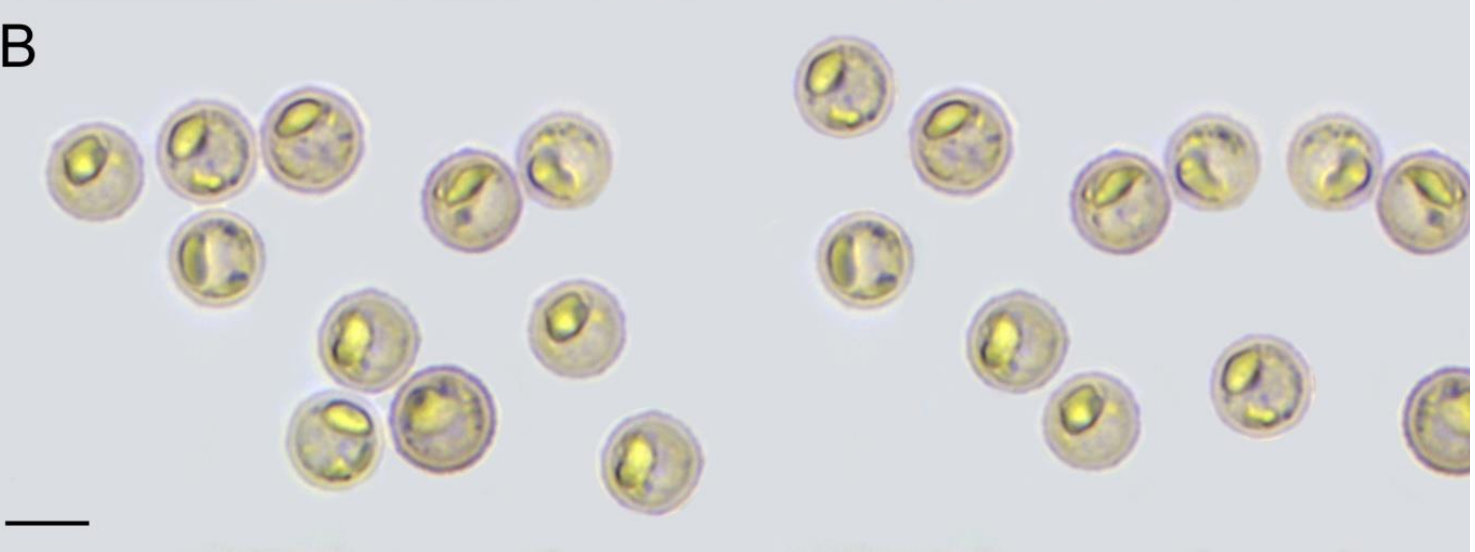

Puc. 1. Cribrara persoonii Nann.-Bremek.

А - загальний вигляд спорокарпа зі зруйнованою перидіальною сіточкою (шкала $20 \mu \mathrm{m}$ ). Б - фрагмент чашечки та перидіальної сіточки (шкала $20 \mu \mathrm{m}$ ). В - спори (шкала $5 \mu \mathrm{m}$ ).

\section{ОБГОВОРЕННЯ}

Серед родин міксоміцетів найбільшою кількістю видів відзначаються Physaraceae (8 видів від виявлених; $22.9 \%$ ), Trichiaceae (7 видів; 20.0\%) та Amaurochaetaceae $\quad(6 ; \quad 17.1 \%)$, поступаються їм Cribrariaceae (5; 14.3\%),
Reticulariaceae $\quad(4 ; \quad 11.4 \%) \quad$ та Stemonitidaceae $(2 ; 5.7 \%)$. Серед родів за кількістю видів найбагатшими виявилися Cribraria Pers. (5; 14.3\%), Arcyria F.H. Wigg., Physarum Pers. та Trichia Haller (по 3 види; 8.6\%). 
У родах Badhamia Hochg. et Gottsb., Comatricha Preuss, Fuligo Haller, Licea Schrad., Lycogala Adans., Paradicheopsis Hertel та Stemonitis Gled. виявлено по 2 види $(5.7 \%)$, решта родів представлені єдиним видом. Представники перших 5 провідних родів утворюють $45.7 \%$ видового складу міксоміцетів ЗШ. Пропорція біоти складає 1:1:7:1.1:2.3:1.9. Співвідношення види / роди складає 1.9 , види / родини - 4.4, роди / родини 2.3 .

\section{Лimepamypa}

1. Dudka I.O., Trikchleb T.A., Romanenko K.O. (2002) Associations of Myxomicetes with Coleoptera (Latridiidae). Ecology and noospherology. 4 (4): 707-712. Doi 10.5943/mycosphere/4/4/7.

2. Heluta V.P. (1989) Fungal Flora of Ukraine. Downy Mildew Fungi. Kyiv: Naukova dumka.

3. Geobotanical zoning of Ukrainian S. S. Republic (1977). Kyiv: Naukova dumka.

4. Leontyev D.V. (2007) Biodiversity analysis in mycology: a textbook. Kharkiv: Osnova.

5. Leontyev D.V., Dudka I.O., Malanyuk V.B., van Hooff J.P.M. (2013) Myxomycetes of nature reserve "Gorgany". Ukrainian Botanical Journal. 70(1): 94-102. Doi: 10.15407/ukrbotj70.01.094ю

6. Leontyev D.V. (2007) Phytocenotic connections of Myxomycetes (Myxomycota) in Gomol'shanskie Lesa National Park, Ukraine. Russ. J. Ecol. 38(3): 214-216.

UDC $582.24(477)$

\section{ПІДСУМОК}

За результатами проведеного дослідження території ЗШ, було виявлено 35 видів міксоміцетів, 3 переважанням серед порядків Physarales та Trichiales, серед родин - Physaraceae та Amaurochaetaceae. Біоту міксоміцетів ЗШ можна охарактеризувати як ксилофільну, 3 вираженим тяжінням до споруляції на деревні сосні. На території заказника виявлено Cribraria persoonii Nann.-Bremek, яка є новим видом для лісостепової зони країни та українського Лівобережжя.

7. Leontyev D.V., Schnittler M., Stephenson S., Novozhilov Y.K., Shchepin O.V. (2019) Towards a phylogenetic classification of Myxomycetes. Phytotaxa 399(3): 209-238. https://doi.org/10.11646/phytotaxa.399.3.5.

8. Poulain M., Meyer M., Bozonnet J. (2011) Les Myxomycètes. Dauphiné-Savoie: Sarl Editions.

9. Rojas C., Stephenson S.L., eds. (2017) Myxomycetes. Biology, Systematics, Biogeography and Ecology. 1st ed. New York; Amsterdam: Elsevier.

10. Sharivskyi. Botanical reserve of the local importance. In: Klimov O.V, Vovk O.G., Filatova O.V., Grama V.M., Podoba I.M., Ulanovsky M.S., Klimov D.O., Fursova T.M., Nadtochiy G.S., Tveretinova V.V., Besedina D.V. Nature reserve fund and system of natural territories and facilities subject to special protection [online]. Available from: http://harkiv.ru/Bogoduhov/Sharivsk128.htm.

\section{BIODIVERSITY AND ECOLOGY OF MYXOMYCETES IN THE REGIONAL BOTANICAL RESERVE "SHARIVSKYI" (KHARKIV REGION, UKRAINE)}

V.O. Viunnyk, D.V. Leontyev

During the study of myxomycete biodiversity in the Sharivskyi Regional botanical reserve, carried out from June 26 to November 15 in 2020, 35 species from 18 genera, 8 genera, 7 orders and 2 subclasses of the class Myxomycetes were recorded. Margalef diversity index (with the decimal logarithm) for the studied biota exceeds 18.6, while Menhinick's index was 4.1; both indexes indicate a relatively high level of diversity. The Shannon index (1.4), the Simpson index (0.04) and Pielou's evenness index (0.3) demonstrate a high level of evenness of the species spectrum in the studied biota. Bright- and dark-spores myxomycetes are represented in the studied biota almost equally (18 and 17 species, respectively). The species richest orders are Stemonitidales and Physarales (8), Trichiales (7), families Physaraceae (8), Trichiaceae (7) and Amaurochaetaceae (6), genera Cribraria Pers. (5), Arcyria F.H. Wigg., Trichia Haller and Physarum Pers. (3 each). Most of species are xylophilic (31; $88.6 \%$ ), only 3 species $(8.6 \%)$ are corticolous, and only $1(2.9 \%)$ is bryophilic. Arcyria pomiformis shows a mixed ecological strategy and develops both on wood and bark of living trees. These data allow us to characterize the myxomycetes biota of the "Sharivskyi" reserve as xylophilous, which is typical for the forest-steppe of Ukraine. Among the substrate-forming species of plants, the richest in myxomycetes is Pinus sylvestris (24 species collected on this plant). On other substrate-forming species the diversity of myxomycetes was much lower: Quercus robur - 7 species collected, Populus tremula - 4, and Fraximus excelsior - 4. Myxomycetes have not been the object of the study on the investigated territory before, therefore all the species are newly recorded there. One of the species, Cribraria persoonii Nann.-Bremek, is the newly recorded for the forest-steppe zone of Ukraine and the Ukrainian Left Bank region. This species was found on dead wood of P. sylvestris.

Key words: ecological groups, moist chamber culture, taxonomic structure, Kharkiv Forest Steppe. 